\title{
Three Ways of Resisting Racism
}

There are undoubtedly more than three ways of resisting racism, but I will talk about three markedly different strategies to do so. Two of these are very widespread, but the third, arguably the most successful one, is much less so.

The two widespread strategies of resisting racism are, broadly speaking, the antirealist and the realist ones. The first one is to deny the existence of races and thus block even the possibility of racist claims. The second one is to grant that races exist but give some kind of considerations about the fact-value gap in order to block the move from talking about racial differences to talking about value differences. I will attempt to outline a way of resisting racism that is weaker than the first but stronger than the second. My claim is that even if we accept that races exist, we can still deny that there are projectible racial differences. And this is enough to block the possibility of racist claims without bringing in the slippery topic of value differences.

I will use some considerations from philosophy of biology to argue for this third way of resisting racism. Biological considerations have been widely used both in support of the antirealist and in support of the realist strategy: both in favor of the claim that races do not exist and in favor of the claim that they do (and of course biology, or rather what is considered to be biology, has also been used in support of racist claims). I am not sure that biological considerations can help us to decide the ontological question about the existence of races once and for all. But I will argue that biological considerations can be used to show that even if races exist, projectible racial differences don't.

\section{The First Way}

The first, and simplest, way of resisting racism would be to deny that races exist (Livingstone 1962, Diamond 1993, Appiah 1992, Appiah and Gutman 1997, Molnar 1992, Zack 1993, 2002, Harding 1993). If there are 
no races, then any racist statement would be meaningless. As David Hull says, "if races do not exist in any significant sense, then it is hard to see how one race can be superior to other races" (Hull 1998, 366, see also Hull 1986). Here, again, we need to distinguish a number of strategies.

Antirealism about race often takes the form of a version of social constructivism: the claim that race is merely a social construct (there are many versions of this claim, but the most influential ones include Appiah 1992, Goldberg 1993). Social constructivism about race comprises a negative and a positive claim: that race has no objective reality and that racial concepts refer to socially constructed categories (Andreasen 2000, 654-55, see also Mallon 2004, 2006). What is important from our point of view is the negative thesis that races have no objective reality: they do not exist.

It is not clear what is supposed to be meant by the claim that races do not exist. A widespread and intuitively plausible way of reading this claim would be to say that classifying individuals in races does not "carve nature at its joints." In short, race is not a natural kind. Racial concepts do not pick out natural kinds, but merely artificial kinds, like the concept of democrats. The division between democrats and nondemocrats does not carve nature at its joints. Nor, so the race-skeptic concludes, do racial terms.

But there are a number of ways in which we can deny that race is a natural kind. I will consider four widespread arguments.

(i) One can argue that no natural kinds exist. Therefore, race, supposedly a natural kind, does not exist either. This is the strategy recently endorsed by Ian Hacking (Hacking forthcoming, Hacking 2007). Resisting realism about natural kinds is a sweeping claim and very few philosophers (let alone racists) would be open to endorse it. Thus, building a way of resisting racism on such a claim does not seem the best way of beating racism.

(ii) The second argument against the claim that race is a natural kind uses a somewhat weaker premise. There may or may not be natural kinds in general. But biological kinds are not natural kinds. Hence, race, supposedly a biological kind, is not a natural kind either. This would be a less radical argument than the previous one as it would deny realism about natural kinds only with regards to the biological domain, remaining silent about nonbiological natural kinds. But why should we accept that biological kinds behave differently from nonbiological ones? What is so special about the biological domain? 
It is a widely held view that biological kinds are indeed very different from nonbiological kinds (Mayr 1959/1994, Dupré 2002, Hull 1986). But this difference does not concern the question of realism about biologi$\mathrm{cal} /$ nonbiological kinds, but the other grand question about natural kinds: essentialism. It has been argued that there is an asymmetry between the biological and the nonbiological domains as far as essentialism is concerned. Water, according to many (Putnam 1975, Kripke 1980), is defined by an essential property, namely, that of being composed of $\mathrm{H}_{2} \mathrm{O}$ molecules. All and only members of this natural kind have the property of being composed of $\mathrm{H}_{2} \mathrm{O}$ molecules and this is true across possible worlds. In contrast, it is not true of biological categories that there is an essential property that all and only members of them have in all possible worldsessentialists and anti-essentialists all seem to agree on this (see, for example, Dupré 2002, Ghiselin 1974, and Hacking 2007 in the former camp as well as Ellis 2001 and Wilkerson 1995 in the latter).

I will say more about what essentialism about biological kinds imply in Section IV. Here it is enough to point out that anti-essentialism about biological kinds does not imply antirealism about biological kinds. Thus, even if the arguments for biological anti-essentialism were fully convincing, and, as we shall see in the next section, they may not be (see Okasha 2002, Griffiths 1999, Walsh 2006), we could not conclude that we should reject realism about biological kinds. In fact, all the classic accounts of biological anti-essentialism presupposed realism about biological kinds (Mayr 1959/1994, Hull 1965, Dupré 2002). But if this is so, then strategy (ii) does not seem to have much support.

(iii) The third argument is that while there may or may not be biological natural kinds in general, subspecies, and, among them, human races are not natural kinds. This is John Stuart Mill's famous strategy (Mill 1843, for a thorough analysis of Mill's account of race see Hacking 2005 and Hacking 2007). According to Mill, "real Kinds" (what we now call natural kinds) share an "endless number" of properties, which are independent of one another. But subspecies (and human races) are not real Kinds: members of one subspecies do not share an "endless number" (or even a vast number) of properties. Species are real Kinds, subspecies are not.

Argument (iii) can be and has been formulated without any reference to Mill's somewhat idiosyncratic terminology. It has been argued that regardless of how one defines species, if one does that in such a way that the 
division between species is clear-cut, then the division between subspecies will be blurry (Wilson and Brown 1953, Edwards 1954, Livingstone 1964, Gould 1977, see also Hull 1998, esp. pp. 363-64 for a good summary). As a result, as Wilson and Brown conclude, the concept of subspecies "outlived its usefulness" (Wilson and Brown 1953, 108).

Take, for example, the influential 'biological species concept': the view that species are "groups of actually or potentially interbreeding natural populations which are reproductively isolated from other such groups" (Mayr 1942, 120; Mayr 1963, 19). If this is the way we should think about species, then what could be the definition of subspecies? Clearly, attempts to give such a definition along the lines of 'groups of actually or potentially interbreeding natural populations which are somewhat reproductively isolated from other such groups' will only give us blurry and unclear ways of defining subspecies.

This more general formulation of argument (iii) is also inconclusive. First, although many natural kind terms have sharp boundaries, nothing guarantees that this must be so. Nothing has been said against the possibility that natural kind terms have vague boundaries (if we think about natural kinds the way Boyd's 'homeostatic property cluster theory' does, for example, then they generally have vague boundaries, see Boyd 1999).

Second, to return to the example of the biological species concept, it seems possible to give a definition of subspecies within this conceptual framework without making this concept too vague. Ernst Mayr himself defines subspecies as "an aggregate of phenotypically similar populations of a species inhabiting a geographic subdivision of the range of that species and differing taxonomically from other populations of that species" (Mayr 2002, 89). Darwin's famous characterization of subspecies as species in the making (Darwin 1858, 52) also survives objections akin to (iii) - although it is extremely problematic as a claim about human subspecies, that is, races (Dobzhansky 1937, Appiah 1992).

(iv) The fourth argument uses an even weaker premise. Subspecies in general may or may not be natural kinds, but human races are definitely not natural kinds. The main consideration here is the famous observation that the genetic difference between human races is smaller than the genetic difference within human races (Lewontin 1970, Lewontin et al. 1984, Nei and Roychoudhury 1993, but see Sesardic 2000 who questions the validity of this argument). Many social scientists and philosophers used these considera- 
tions as the basis for their antirealism about race (see esp. Appiah 1992, 1996).

The Achilles heel of (iv) is that it is not clear that genetic features have any special status in deciding whether something is a natural kind. It has been pointed out that the genetically coded and the developmental part of evolutionary explanations cannot and should not be detached from each other (Griffiths and Grey 1994, Oyama et al. 2001, cf. Godfrey-Smith 2000, Nanay 2002, Sterelny, Smith and Dickison 1996). More precisely, according to 'developmental system theory', there is no sharp distinction between 'genetic' and 'environmental' developmental causes. But if this is so, then facts about comparative genetic similarity cannot by themselves settle the question whether human races are natural kinds.

As we have seen, none of arguments (i)-(iv) seem unproblematic. But even if we grant what they are supposed to show: that human races are not natural kinds, it still does not block the possibility of racist claims.

The most important way of salvaging a realist conception of race while denying that race is a natural kind is to insist that race is a cultural (and not a biological) category. The claim is that racial classifications are not based on anything biological: it is not something biological that makes it the case that a certain individual is a member of a certain race, but something about the culture, behavior, or habits of this race and this individual. Racial concepts latch onto something real in the world, but this 'something real' is not defined in biological but in cultural terms.

There is an obvious worry about this strategy of resisting racism. Even if race does not have biological reality, if it has cultural reality, then racist claims can be reformulated accordingly. This version of racism is often called 'cultural racism'. Although many racist claims are founded on some kind of assumptions about the biological nature of race, this is not a necessary feature of the racist discourse. One could make racist claims while referring to races as culturally (and not biologically) defined categories. While denying that racial classification has any biological foundation defuses some racist rhetoric, it is helpless in the face of others.

\section{The Second Way}

So suppose that we accept that races exist. How can we now resist racism? The standard strategy here is to point out that the existence of racial differences does not imply any kind of value difference. This is the second way of resisting racism. ${ }^{1}$ 
We have seen in the last section that there are a number of ways of arguing that races do not exist. Similarly, there are a number of ways of arguing that races exist. First, one can resist any of the four arguments (i)-(iv) in favor of the claim that race is not a natural kind. Many of these considerations are supported by biological arguments. Ernst Mayr, probably the most important evolutionary biologist of the second half of the last century, goes as far as saying that "those who subscribe to [the view that races do not exist] are obviously ignorant of modern biology" (Mayr 2002, 89) and later: "Recognizing races is only recognizing a biological fact" (Mayr 2002, 90). Similar views have been expressed by most biologically inclined theorists of race (just a couple of examples: Kitcher 1999; Andreasen 1998, 2000; Hardimon 2003). It is worth noting that at least some of them hold that this view, biological realism about races, does not exclude a version of social constructivism (Andreasen 2000), which I analyzed in the last section as the default antirealist strategy).

But even if one denies that races are natural kinds, one can still assert that they exist: that they are not just our arbitrary way of grouping individuals. This is the view Ian Hacking and Philip Kitcher have argued for recently (Hacking 2005, Kitcher 2007). They claim that race is a "statistically useful" (Hacking) or "pragmatically useful" (Kitcher) category. Their argument rests on the recent phenomenon of 'race-based medicine' (on why this widely used term is question-begging, see Hacking 2005, 109).

It has been discovered recently that some heart medications work much better on members of some races than on others. It is not clear whether this statistical correlation is due to genetic or cultural (say, nutritional) reasons. Hacking points out that the correlation between race and the efficacy of these medicines is not only statistically significant, it is also statistically useful: as he dramatically states, "race is a matter of life and death" (Hacking $2005,108)$. Thus, even if race is not a natural kind, it is a statistically significant and statistically useful class. It exists although it is not a natural kind. ${ }^{2}$

If one is persuaded by any of these realist arguments about race, the question arises: what logical space remains for resisting racism within this realist framework? The antirealist had a short and simple argument against racism: if races do not exist, racist rhetoric is impossible. But what can the realist say?

The standard strategy here is to point out that the existence of racial differences does not imply any kind of value difference. An important 
version of this strategy is to hold that different races are better at different things. As Ernst Mayr, one of the champions of the biological concept of race, says:

$[\mathrm{N}]$ othing could be more meaningless than to evaluate races in terms of their putative "superiority." Superiority where, when, and under what circumstances? During the period of the development of the human races, each one became adapted to the condition of its geographic location. Put a Bushman and an Eskimo in the Kalahari Desert and the Bushman is very much superior. (Mayr 2002, 91)

Race A may be better at Xing than race B, but race B may be better at Ying than race $\mathrm{A}$. And who are we to tell that the ability to $\mathrm{X}$ is somehow more valuable than the ability to $\mathrm{Y}$ ?

This strategy is of course vulnerable to being exploited by racist theorizing. If different races are better at different things, then maybe some races are better at those things that really count, whereas other races are better at useless things - a strategy implicitly employed in Entine (2000) as well as by a number of contributors to the debate that became known as the 'IQ controversy' (Block and Dworkin 1976). And from here, racism is a short and easy step away.

An interesting version of realism about race needs to be discussed separately as it seems to provide a different and maybe more promising way of resisting racism. The view is the following. There are races and they can be identified with the help of biological considerations. But the racial categories that biology gives us are not the same as our everyday folk concepts of race (Pigliucci-Kaplan 2003). ${ }^{3}$ As David Hull states:

[T] he subdivisions of Homo sapiens that experts recognize do not come close to coinciding with the "races" of ordinary people. Several groups of people who are considered Caucasoids by anthropologists would rouse all the anxiety and hostility in ordinary white racists that blacks do. Their skin is black. They look black. But technically, they are Caucasoids. But such observations are not likely to persuade the members of the admissions committee of an all-white country club. (Hull 1998, 365)

If the biologically grounded concept of race is different from the everyday concept of race, then there is a new and promising strategy for resisting racism. The concepts exploited in racist statements are folk concepts. Thus, biologically grounded racial categories cannot give us any justifications 
for racist claims - these categories are different from the ones exploited in racist rhetoric. This view is a version of realism about race: it states that there are biologically defined races, but it could also be considered to be a version of antirealism as far as the folk conception of race is concerned: these folk concepts do not pick out any 'real' categories in nature.

Although this version of realism about races seems more promising than other realist attempts, it is unlikely to block racist rhetoric. Take the argument presented in Entine (2000). The structure of Entine's argument is that race $\mathrm{A}$ is (on average) better at Xing (which he implicitly judges to be a not very valuable ability) than race $B$. The concepts of 'race A' and 'race B' are folk concepts (I'll use scare-quotes to indicate this), thus, his claim is not about categories that have any biological reality (PigliucciKaplan 2003, 1167). But the empirical considerations Entine uses are about categories that are supposed to have biological reality: some biologically defined race $\mathrm{C}$ within 'race' $\mathrm{A}$ that is (on average) much better at Xing than 'race' B. Thus, even if we embed this biologically defined race $\mathrm{C}$ in a class that has no biological reality ('race' $\mathrm{A}$ ), if non- $\mathrm{C}$ members of A are not much worse at Xing than members of B, then it will still be true that 'race' $A$ is better at Xing than 'race' $B$, in spite of the fact that neither 'race' A not 'race' B have any biological reality. And from here it would be easy to argue that this difference between these two 'races' is a value difference. Disambiguating the biological and the folk conception of race still does not block all racist arguments.

To sum up, the general worry about the entire second strategy of resisting racism is that once we have acknowledged the existence of racial differences, it will be very difficult to block arguments that present these racial differences as value differences.

So far, the roadmap for resisting racism looks like this:

Question 1: Do races exist?

No: Racism is a nonstarter

Yes:

Question 2: Is the difference between races a value difference?

No: Racism is a nonstarter

Yes: This is where racism starts 


\section{The Third Way}

Some may be dissatisfied by both of these options. One may think that denying the existence of races is too strong a strategy and biologists may give us some reason to question its feasibility. But one may also think that construing the difference between races as value-free is too weak a strategy and it could easily slide into racism. We need a third strategy that is neither too strong nor too weak.

I will argue that there is another, much less-explored way of resisting racism. If we accept that races exist, the next question we should ask is whether there are projectible racial differences. And it is only if we respond affirmatively that the question of value neutrality arises. The third way of resisting racism is to deny that racial differences exist. So the road map will be the following:

Question 1: Do races exist?

No: Racism is a nonstarter

Yes:

Question 2: Are there projectible racial differences?

No: Racism is a nonstarter

Yes:

Question 3: Is the difference between races a value difference? No: Racism is a nonstarter

Yes: This is where racism starts

It is important to note the structure of my argument. I am not committed to saying that races exist. Maybe they don't; maybe some of the arguments (i)-(iv) I outlined in section I are correct. But even if they do exist, we have a way of resisting racism without resorting to the strategy of insisting that racial differences are not value differences. Even if races do exist, there are no projectible racial differences.

But how can we accept that races exist and still deny that there are projectible racial differences? Here we need to differentiate between two ways of talking about the difference between groups of individuals. 
Suppose that the claim is that race A is better at Xing than race $\mathrm{B}$ (there is no shortage of overtly or covertly racist claims of this kind; a recently popular one can be found in Herrnstein and Murray 1994). Thus, the claim is that As are better Xers than Bs. What does this mean? It can mean two things. First, it can mean that the worst A is still better than the best B at Xing. Or, second, it can mean that on average, As are better Xers than Bs.

The first of these two options is not viable: racial differences are not of this kind. There is no alleged 'racial difference' that would follow this pattern. It has been repeatedly pointed out that there is always an overlap between the properties of members of two different races - regardless of which properties we are talking about: the worst Xer of the 'better Xer race' is always worst than the best Xer of the 'worse Xer race' (Mayr 1959/1994, Molnar 1992 - interestingly, this is also acknowledged by those who are flirting with racism, see Herrnstein and Murray 1994). Thus, although we may be able to talk about differences of this kind between some groups of people, we can't talk about racial differences this way.

Thus, we are left with the second option, namely, that on average, As are better Xers than Bs. But what does this mean?

In order to decide what this claim means, we need to ask a further question: what makes it the case that, on average, As are better Xers than Bs. Here, again, we have two options.

The first option would be to say that there is something about As in general that makes it the case that on average As are better Xers than Bs. In other words, As are better Xers than Bs qua being As. The second option would be to say that there is nothing about As in general that makes it the case that on average As are better Xers than Bs. As are not better Xers than Bs qua being As. It just happens to be the case that if we take the average Xing capacity of As and the average Xing capacity of Bs, the former is higher.

Take the first option briefly. If As are better Xers than Bs qua being As, then the difference between As and Bs in terms of Xing potential is a projectible difference (see Goodman 1955, 82ff; Quine 1969 on the concept of projectibility). And the projectibility of racial differences is exactly what seems to be needed for making racist claims: racist claims are supposed to be about certain properties of members of a certain races qua being members of that race. Racist claims are supposed to apply to 
those members of the race in question who have not been born yet (again, this is a clear assumption in Herrnstein and Murray 1994).

A natural way of filling in the details of this first option to explain what makes it the case that on average As are better Xers than Bs is the following: there is a property As have and Bs do not have that makes it the case that As are better at Xing than Bs (on average).

Thus, the picture is the following. There is a property, call it $\mathrm{P}$, that is such that all and only members of race $\mathrm{A}$ have instantiations of $\mathrm{P}$. Members of race $B$ do not have instantiations of $P$. And it is the having instantiations of $\mathrm{P}$ that makes it the case that As, on average, are better Xers than Bs. This property, P, could be a genetic property, a phenotypic biological property, or a nonbiological, say, behavioral or cultural property. Importantly, $\mathrm{P}$ is a property that not only current members of race $\mathrm{A}$ have, but all past and future members, otherwise racial differences would not be projectible. Also, if we veer away a bit from the actual world, members of race A should not stop having property $\mathrm{P}$, as, again, this would jeopardize the projectibility of these racial differences. In short, $\mathrm{P}$ is an essential property of race A.

I said it is a natural way of filling in the details of the first option to explain what makes it the case that on average As are better Xers than Bs. It is not the only way. Richard Boyd argues that there is no property that all and only members of a species have in common. According to his 'homeostatic property cluster theory', the members of a kind share a cluster of similar properties, but no single property is necessary for membership in this kind (Boyd 1999). It is important to note, however, that Boyd's 'homeostatic property cluster theory' is also a version of essentialism (at least according to him). The arguments I give about the essentialist way of talking about racial differences in the next section can all be rephrased in terms of Boyd's terminology.

Property $\mathrm{P}$ does not have to be something observable, like skin color. Essential properties, at least according to Putnam and Kripke, are rarely observable: the essential property of water, that is, its molecular structure, for example, is not observable (at least not without some very special equipment). So property $\mathrm{P}$, in claims of projectible racial differences, does not have to be an observable property: it can also be some unobservable property or even the propensity to have another, observable, property $\mathrm{P}^{*}$. 
It is important to clarify the structure of my argument. More specifically, it needs to be emphasized again that the racial differences that the presence or lack of property $\mathrm{P}$ underwrites do not have to be absolute. Again, the projectible racial differences in question are differences of average Xing capacity. Some As are worse Xers than some Bs, but on average As are better Xers than Bs. I argue that in order for these racial differences to be projectible, there needs to be a property that All As have and all Bs lack that accounts for this difference in average Xing capacity. An analogy would be the following. Suppose that American coins, on average, land heads more often than British coins. It's not the case that they all land heads and British coins all land tails; just that on average, there is a difference. If this difference is a projectible one, there must be a property $\mathrm{P}$ that makes this the case. And this property is being headbiased: a property that, per hypothesi, American coins have but British coins don't. Again, P does not have to be, and indeed in this case, it is not, an observable property.

In other words, the first option of answering the question about what makes it the case that As are better at Xing than Bs implies a version of essentialism. Property P, which makes it the case that As are better at Xing than Bs is supposed to be an essential property of race A: a property all and only members of race A have. I will criticize this first option in the next section. But before proceeding, I want to rule out the second option for answering the question about what makes it the case that As are better at Xing than Bs.

The second option for answering this question would be to say that there is no property that As have and Bs lack that would make it the case that As are better at Xing than Bs. But the momentary distribution of As' Xing ability and Bs' Xing ability is such that if we take the average of the Xing ability of those people who we know to be members of A and we also take the average of the Xing ability of those people who we know to be members of $\mathrm{B}$, the former is higher than the latter.

There is nothing wrong with this strategy, but it will not yield any projectible racial differences either. It is important to notice that we can only compare the average Xing ability of those As and those Bs that we have observed. But if this is so, then this comparison will give no justification for saying anything about the Xing abilities of a new or unknown A. Hence, it will not give any justification for saying anything about the Xing abilities of As in general. It will not give any justification for saying anything about the Xing abilities of As qua As. It will only give justification for 
saying something about the Xing abilities of those members of A (or B) who have been observed. Thus, this option, while viable, would be utterly useless for making racist claims. If racial differences were to boil down to differences of this kind, this would make racist claims impossible.

But the first (essentialist) option for answering the question about what makes it the case that As are better at Xing than Bs could indeed be used for making claims about As qua As. Thus, I need to examine whether the first option for answering this question is a viable one.

\section{Realism and Essentialism}

The essentialist option for answering the question about what makes it the case that As are better at Xing than Bs was the following. There is a property, $\mathrm{P}$, that is such that all and only members of race A have $\mathrm{P}$. Members of race $\mathrm{B}$ do not have $\mathrm{P}$. And it is having $\mathrm{P}$ that makes As better Xers than Bs. I call this option the essentialist one, as $\mathrm{P}$, conceived this way would count as an essential property of race A. I would like to remain neutral about what this property, $\mathrm{P}$, could be: it could be a genetic property, a phenotypic biological property, or a nonbiological, say, behavioral or cultural property.

I aim to point out that this option for answering the question about what makes it the case that As are better at Xing than Bs does not work because there is no property $\mathrm{P}$ that would be able to play the role it is supposed to play according to the essentialist proposal. More specifically, there is no property $\mathrm{P}$ that would both be such that all and only members of race A have it (and do so necessarily) and that would also be responsible for the difference in the Xing abilities of As and Bs. In other words, the essentialist option is not viable. There are no projectible racial differences.

Let me pause for a moment to clarify the structure of the argument. The claim I defend in this paper is that even if races exist, there are no projectible racial differences. And we have seen that there are two distinct ways of defending the claim that races exist: the first one is to claim that races are natural kinds: presumably biological categories. The second way of defending realism about race is to claim that race is not a biological but a cultural category: racial concepts latch onto something real in the world, but this 'something real' is not defined in biological but in cultural terms. Although the first strategy is more widespread (and, as a result, I will spend more time addressing it), the second strategy should not be ignored.

Depending on the way we think of the reality of races, that is, whether we think of them as biological or cultural categories, the essen- 
tialist way of explaining racial differences will also be different. If race is not a biological but a cultural category, then the essential property that all and only members of race A have is presumably not a biological, but a cultural property (otherwise it is hard to see why race would not be a biological category). But what could possibly be a cultural or behavioral property that all and only members of race $\mathrm{A}$ have and do so in all possible worlds? Supposing that in twenty generations, members of race A will have the same cultural or behavioral property as they do now would imply extreme pessimism about the possibility of social change. The world and our society can change and so can the cultural and behavioral properties of members of race $\mathrm{A}$.

One could argue that we may be able to salvage this cultural version of an essentialist way of explaining racial differences if we consider potential essential properties such as being subject to a certain kind of social interaction/discrimination. Thus, the property all and only members of race A would have is the property of being treated by others in a certain way in virtue of being perceived to be a member of race A. The problem with this suggestion is, again, that it would imply extreme pessimism to suppose that this property is one that all and only members of race A have in the past, present and future, as it would imply denying the possibility that the way someone is being treated by others in virtue of being perceived to be a member of race A cannot change. If we want to maintain hope in the possibility of social change, then this property is unlikely to be an essential one. But maybe we should modify this attempt to salvage the cultural version of an essentialist way of explaining racial differences and consider the potential essential properties not of being subject to a certain kind of social interaction/discrimination, but rather of being a descendent of people who were subject to a certain kind of social interaction/discrimination. The problem with this suggestion is that this property, although, arguably, all and only members of race A have it and this may even be so necessarily, it is unlikely to be a property that would do much causal work. And as we have seen, according to the essentialist way of explaining racial differences, there is a property that is both such that all and only members of race $\mathrm{A}$ have it (and do so necessarily) and that makes it the case that As are better at Xing than Bs. It is unclear how the property of being a descendent of people who were subject to a certain kind of social interaction/ discrimination could make it the case that As are, and will always be, better Xers than Bs. 
So much about the cultural version of the essentialist way of explaining racial differences. This leaves us with the mainstream version of realism about races, according to which races are biological categories. According to the essentialist way of explaining racial differences, there is a property that members of this biological category have in common that would make it the case that As are better at Xing than Bs. Here my strategy will be the following. If we accept the widespread anti-essentialist claims about the biological domain, then we are done: if races are biological categories and if, as the biological anti-essentialists claim, biological categories do not have essential properties, then races do not have essential properties. Thus, we cannot explain racial differences in an essentialist fashion. We can conclude the argument here. The problem is that not everyone accepts anti-essentialism about the biological domain, so I will address possible ways of resisting the 'anti-essentialist consensus' and point out that although some of them may be viable in general, they cannot provide us with essential properties for races.

First we need to be clear about what 'essential properties' are. One big question about natural kinds in general is whether they have essential properties: properties all and only members of a natural kind have in all possible worlds. Hilary Putnam and Saul Kripke argued that they do (Putnam 1975, Kripke 1980). However, biology has always been considered to be a problem case for essentialism or at least a potential exemption. According to the traditional and rather strong "anti-essentialist consensus" (Okasha 2002, 195, Walsh 2006, 325) among biologists and philosophers of biology, at least regarding biological kinds, essentialism is false (Dupré 1993, 2002, Hull 1965, Ghiselin 1974, Hacking 2007). Putnam and Kripke may be right about chemical kinds, but biological kinds do not have (and cannot have) any essential properties (Wilkerson 1995, Ellis 2001).

It is not an easy task to pin down what is meant by essentialism about biological kinds. A couple of preliminary remarks need to be made. First, there are a number of potential definitions for essentialism about kinds. I will use the most general of these. Richard Boyd identified a widespread and fairly strong version of essentialism, according to which natural kinds "must possess definitional essences that define them in terms of necessary and sufficient, intrinsic, unchanging, ahistorical properties" (Boyd 1999, 146). Essential properties in, say, chemistry may all be intrinsic, unchanging and ahistorical. But it is not clear that essential biological properties need to satisfy any of these three requirements. In fact, a rather easy way of arguing 
against essentialism about biological kinds is to point out that biological properties are extrinsic, historical, and they change over time, because biological entities are evolving over time. I don't think arguments of this kind will defeat essentialism about biological kinds. A new wave of biological essentialists all seek to specify essential properties of biological kinds that are extrinsic and that are neither unchanging nor ahistorical. ${ }^{4}$ The simple argument from the observation that biological entities are evolving over time cannot be used to argue against these versions of biological essentialism.

Thus, if we want a target that is worth arguing against, we need to weaken this strong definition of essentialism. As most of the new essentialists, I am also happy to go along with David Hull's characterization, according to which "each species is distinguished by one set of essential characteristics. The possession of each essential character is necessary for membership in the species, and the possession of all the essential characters sufficient" (Hull 1994, 313). I will use Hull's definition as my starting point for characterizing kind-essentialism in what follows.

Third, essentialism about kinds is a complex thesis that goes beyond the simple claim that there are some properties that all and only members of a natural kind have in all possible worlds. Marc Ereshefsky specified three tenets of any version of essentialism about kinds:

One tenet is that all and only the members of a kind have a common essence. A second tenet is that the essence of a kind is responsible for the traits typically associated with the members of that kind. For example, gold's atomic structure is responsible for gold's disposition to melt at certain temperatures. Third, knowing a kind's essence helps us explain and predict those properties typically associated with a kind. (Ereshefsky 2007, section 2.1)

The essentialist option for accounting for racial differences seems to have to endorse all three of the tenets of essentialism. All and only members of race $\mathrm{A}$ have property $\mathrm{P}$ and it is property $\mathrm{P}$ that is causally responsible for (thus, it can also help us to explain) the difference in the average Xing ability of As and Bs.

The second and the third tenets of essentialism are often underrated, so it is important to point out that they are as important as the first one. The third tenet of essentialism is the following. "Knowing the essence of a kind [...] allows us to predict and explain the properties associated with the members of a kind. For instance, the atomic structure of gold provides the basis for explaining why gold conducts electricity, and it allows us to 
predict that a particular chunk of gold will conduct electricity" (Ereshefsky forthcoming, 1). Or, as Philip Kitcher says, "natural kinds are distinguished by some special underlying feature that explains the behavior of members of this kind-like atomic number, for example, in the case of the elements" (Kitcher 2007, 294; Dupré 2002, 176-81; Wilson et al. forthcoming; see also Platts 1983 for a classic summary and Okasha 2002, p. 203 for some critical remarks). Explanations come in many forms (see Van Fraassen 1980 for a classic analysis) so in order for the third tenet to be meaningful at all, we may need to add that this explanation is supposed to be a causal explanation.

The second tenet is about causal responsibility: as Ereshefsky says, "a kind's essence causes the other properties associated with that kind. The essence of the natural kind gold, for example, is gold's atomic structure. [.. .] the atomic structure of gold causes pieces of gold to have the properties associated with that kind, such as dissolving in certain acids and conducting electricity (Ereshefsky forthcoming, 1). What we say about this second tenet depends on what we say about the relata and properties of (singular) causation. If one holds that properties play no causal role (as Davidson (1970) suggests), then we have reason to doubt the second tenet - not only in the case of biological kinds, but in the case of any kinds. But let us, for the sake of argument, grant that properties play a role in causation, either as constituents of the relata (as long as these relata are taken to be facts, states of affairs or Kimian events) or as the properties in virtue of which one event causes another one (Nanay 2009). The question we now need to ask is whether the alleged essential properties are causally relevant.

Why are the second and the third tenets of essentialism relevant in our discussion of the essentialist way of explaining racial differences? After all, if an explanation of why As are better Xers than Bs qua being As falls short of some essentialist premises, it could still give us projectible racial differences. The reason why the second and the third tenet matter is that whatever property of As makes it the case that As are better Xers than Bs, it should make it the case that As are better Xers than Bs: it should be causally relevant in bringing about this racial difference. And it should also help us to explain the existence and projectibility of this racial difference.

It is important to note that even if we refrain from positing that the essential property would be such that all and only members of a kind would possess it, like Richard Boyd's 'homeostatic property cluster theory' 
would, the second and the third tenets are still very important (maybe even more so). Boyd explicitly states that "the homeostatic clustering of properties [...] is causally important" (Boyd 1999, 143).

We have seen that it is easy to use the supposed "anti-essentialist consensus" about biology to argue against the essentialist way of explaining racial differences. As essentialism about the biological domain is held to be false and as race is by supposition a biological category, if we put these two claims together, what we get is that the essentialist way of explaining racial differences does not work.

The problem with this strategy is that the "anti-essentialist consensus" is not as strong as it may seem. First, it is not clear that there are any knock-down arguments against essentialism about biological kinds (but see Nanay (forthcoming a) and Nanay (forthcoming b) for some possible candidates). It has been pointed out that some of the classic anti-essentialist arguments do not in fact work (Sober 1980, 356; Okasha 2002, 195-96; Walsh 2006, 431).

More importantly, in the last couple of years, more and more philosophers have argued for a version of essentialism about biological kinds. Paul Griffiths, for example, argues that biological kinds have "essential relational properties" - not essential intrinsic properties, and claims that if we accept that essential properties can be relational, then all the traditional considerations against essentialism about biological kinds lose their appeal (Griffiths 1999, 209; for a similar claim, see Okasha 2002; the idea of using relational properties for defining biological kinds, not necessarily in an essentialist manner, comes from Matthen 1998, Millikan 1999, and Elder 1995).

Instead of trying to find a convincing argument for anti-essentialism about biological kinds in general, my aim here is to establish a much narrower point about the possibility of an essentialist account of explaining racial differences. And my claim is that even if it is true of some biological categories that there is an essential property such that all and only members of a certain biological category have this property and they do so necessarily, races are not among biological categories of this kind.

My claim is that the relational properties that have been proposed as potential essential properties of biological kinds either fail to be such that all and only members of race A have them and they do so necessarily, or if they don't, then they are unlikely to be causally efficacious. In other words, 
these potential essential relational properties either fail to satisfy the first tenet of essentialism, or if they do so, they still fail to satisfy the other two tenets of essentialism; most importantly, they are unlikely to play any causal role.

Here are the three most plausible candidates that have been proposed for being the essential relational properties of some biological categories (Okasha 2002, 210): "being a member of a group that is able to interbreed successfully with one group of organisms and not another;" "being a member of a group that occupies a particular ecological niche;" and "being a member of a particular segment of the genealogical nexus." These properties are supposed to be essential properties that all and only members of a certain species, as opposed to races, have. But it is easy to see that regardless of whether these are in fact good candidates for essential properties for species, they will not qualify as essential properties for races. The first property is clearly not viable as an essential property for races as a member of a race can interbreed with any other races. The second property is not an option either as members of the same race may occupy very different ecological niches. Similarly, it is not true that all and only members of a race are "members of a particular segment on the genealogical nexus."

Thus, those properties that seem to be the most likely candidates for being the relational essential properties for biological categories cannot be used to provide an essential property for races: it will not be true that all and only members of a race have these and they do so necessarily. But this does not mean that there are no properties that all and only members of a race have (and they do so necessarily). Here are a couple of possible examples.

A simple candidate for a property that is undoubtedly such that all and only members of race A possess it, and they do so necessarily, is the property of being a member of race $\mathrm{A}$, but this property cannot be used for explaining the existence and projectibility of racial differences. To say that what makes it the case that As are better at Xing than Bs is that As are members of race $\mathrm{A}$ is no explanation at all: it is just reiterating the claim that racial differences are projectible without explaining what makes them projectible.

Here is a better candidate for a better potential candidates for a relational essential property that all and only members of race A possess. Take the relational property of being a member of a population with such and such evolutionary history (suggested by Griffiths 1999). To fit the question about 
racial differences, we should modify the property slightly: the candidate essential property then is of being a member of a race with such and such evolutionary history. Putting aside the question whether races have (uniform) evolutionary history at all, it seems plausible to suppose that this is a property that all and only members of race A have. So the first tenet of essentialism seems fine. But the second and the third tenet are unlikely to be satisfied: it is not clear how an individual's, a*'s, property of being a member of a race with such and such evolutionary history could be causally efficacious (see Nanay (forthcoming a) for a detailed argument). Various properties of the evolutionary history of a*'s token lineage may be causally relevant in bringing about a*'s properties and especially those properties that are responsible for a*'s Xing abilities. But the property of being a member of a race with such and such evolutionary history is not causally efficacious?

It is important to emphasize that I do not deny that relational properties in general can be causally efficacious in making it the case that As are better at Xing than Bs. What I aimed to point out is that those properties that have been given as candidates for relational properties that all and only members of a race have lack this causal efficacy. There are causally efficacious properties of individuals. And there are properties that all and only individuals of race A have. But there does not seem to be any overlap between these two sets of properties.

The essentialist way of explaining why As are better at Xing than Bs took the form of a conjunction: There is a property, call it $\mathrm{P}$, that is such that all and only members of race $A$ have instantiations of $P$. And it is the having instantiations of $\mathrm{P}$ that makes it the case that As, on average, are better Xers than Bs. I aimed to show that there is no candidate for property $P$ that would satisfy both conjuncts. The essentialist account of explaining why As are better Xers than Bs fails.

\section{Races Without Racial Differences}

What can we then say about Xing capacities and the differences thereof? The first thing we should say is that comparisons between Xing abilities should be made between the Xing abilities of individuals. Individuals have Xing abilities, races don't. Thus, we can say that $a^{*}$, who is a member of race A may be better at Xing than $b^{*}$, a member of race B. 
But it makes no sense to make comparisons between the Xing potential of races. Races, even if we accept that they exist, do not have Xing potentials. We can, of course, talk about the average Xing capacity in race A - nothing could stop the statistically minded from doing so. But it is important to keep in mind that 'the average Xing capacity in race A' is about the average Xing capacity of the observed members of race A. It is purely our statistical abstraction that we arrive at on the basis of a limited number of observations of members of race A. It does not say anything about how unobserved members of race A will perform X. We do not get projectibility on the basis of statistical averages (Mayr 1959/1994).

A final worry about the claim that there are no projectible racial differences is that it is not clear how it squares with the recent discussion about what is known as 'race-based medicine'. As we have seen in Section II, it has been shown that some heart medications work more reliably on members of one race than on members of another race. What is this, if not a clear and very important racial difference?

My response is that this is not a racial difference at all. The medication works on a certain individual, $\mathrm{a}^{*}$, because of $\mathrm{a}^{*}$ 's specific properties. And it fails to work on another individual, $b^{*}$, because $b^{*}$ has some other properties. We don't know what kind of properties these are, genetic, environmental or nutritional. Hopefully, science will find out one day. But regardless of what kind of property is causally responsible for the fact that this medication works in the case of some people but not others, we have no reason to suppose that the medication works in the case of a* in virtue of the fact that $\mathrm{a}^{*}$ is a member of race A. If it turns out that the property in virtue of which some people can be treated with this medication successfully is a nutritional or an environmental property, then this property is clearly independent of the question of what race this person belongs to. And if the property is a genetic one, then the difference is not a racial difference either, since it has been pointed out that genetic difference between human races is smaller than the genetic difference within human races (Lewontin 1970, Lewontin et al. 1984, Nei and Roychoudhury 1993). Either way, there is a difference between people in the way the medicine works, but we have not reason to suppose that there is a difference between races.

And if we can't talk about racial differences, then we can't make racist claims either. 


\section{Conclusion: Resisting Sexism}

This paper was about a new strategy for resisting racism. But if we accept this strategy, that of denying that there are projectible racial differences, even if there are races, it could be applied to other important domains. Most importantly, it could also be used to resist sexism.

If the argument I presented here is correct, then we can run a parallel argument that would give us a new way of denying the existence of not racial but of sex differences. In other words, the argument presented in this paper could be modified in such a way that we can conclude that statements such as men are (on average) better at Xing than women will make no sense.

As in the case of racial differences, this claim comes with a proviso: if it turned out that each woman has an instantiation of property, $\mathrm{P}$, and no men have instantiations of this property and if $\mathrm{P}$ is not a purely nominal property (such as being a woman), then we can say that there is a sex difference: women have P, whereas men don't. But it is extremely unlikely that we find any such property. Even the existence/lack of a Y chromosome has shown to be a contingent marker of being a man/woman.

Note that the first strategy of resisting racism, the strategy of denying that there are races cannot be extended to sexism in a straightforward manner. If, however, we accept the argument I gave in this paper for resisting racism, the argument for resisting sexism comes for free. The possibility of applying my argument against racism in the case of sexism seems to indicate that it is a more robust strategy than the others. The third way of resisting racism may give more trouble to the racist than the other two. ${ }^{5}$

Syracuse University

Bence Nanay

\section{Notes}

1. It is worth noting that the first and the second ways of resisting racism are not mutually exclusive. David Hull, for example, gives an antirealist as well as a realist argument in the very same paper: the structure of his claim is that races do not exist, but even if they did, they would not coincide with what our everyday racial concepts pick out (Hull 1998).

2. Hacking and Kitcher claim that race is pragmatically (or statistically) useful in a biological, or medical, context. But it could also be argued that race is pragmatically useful 
in a social context (Shelby 2006; Kitcher 2007, 311). Affirmative action would not be possible without having at least some form of realism about race and nor would any kind of sociological research into the effects of racial discrimination. Further, as Shelby emphasizes, race may foster solidarity among people who suffer the consequences of injustices of the past (or the present). These arguments need not (and in fact, usually do not) rely on a biological concept of race, but they do presuppose some form of realism about race.

3. This duality may also be in the background of Linda Alcoff's distinction between race and ethnicity, although according to Alcoff the relationship between the two are much more complex, as ethnicity has been notoriously racialized at least in some countries (Alcoff 2005).

4. Griffiths 1999; Boyd 1999; Okasha 2002; see Walsh 2006 and Devitt ms for a different way of resurrecting essentialism about natural kinds and Nanay forthcoming a, Nanay forthcoming $b$, and Ereshefsky ms. for objections to these projects.

5. This paper grew out of the discussion at my Ph.D. seminar on natural kinds at Syracuse University. I'm grateful for Linda Alcoff's comments.

\section{REFERENCES}

Alcoff, Linda Martín 2005. Visible Identities: Race, Gender, and the Self. Oxford: Oxford University Press.

Andreasen, Robin 1998. "A new perspective on the race debate," British Journal for the Philosophy of Science 49: 199-225.

. 2000. "Race: Biological Reality or Social Construct?" Philosophy of Science 67: 653-66.

Appiah, K. Anthony 1992. In My Father's House. New York: Oxford University Press.

. 1996). "Race, Culture, Identity: Misunderstood Connections" in K.A. Appiah and A. Gutman, eds., Color Conscious: The Political Morality of Race. Princeton: Princeton University Press, 30-105.

Appiah, Anthony and Amy Gutman 1997. Color Conscious. Princeton, NJ: Princeton University Press.

Block, Ned and Gerald Dworkin, eds. 1976. The IQ Controversy. New York: Pantheon.

Boyd, Richard 1999. "Homeostasis, Species and Higher Taxa," in R. Wilson, ed., Species: New Interdisciplinary Essays. Cambridge, MA: The MIT Press, 141-86.

Darwin, Charles 1859. On the Origin of Species, Cambridge, MA: Harvard University Press.

Devitt, Michael ms. "Resurrecting Biological Essentialism."

Diamond, Jared 1993. "Race Without Color," Discover 15: 82-89.

Dobzhansky, Theodosius 1937. Genetics and the Origin of Species. New York: Columbia University Press.

Dupré, J. 2002. Humans and Other Animals. Oxford: Oxford University Press.

Edwards, J.G. 1954. "A New Approach to Infraspecific Categories," Systematic Zoology 3: $1-20$.

Elder, Crawford L. 1995. "A different kind of natural kind," Australasian Journal of Philosophy 73: 516-31.

Ellis, Brian 2001. Scientific Essentialism. Cambridge: Cambridge University Press. 
Entine, Jon 2000. Taboo: Why Black Athletes Dominate Sports and Why We Are Afraid to Talk About It. New York: BBS Public Affairs.

Ereshefsky, M. 1998. "Species pluralism and anti-realism," Philosophy of Science 65: $103-20$.

. 2007. "Species," in E.N. Zalta, ed., The Stanford Encyclopedia of Philosophy (Fall 2007 edition).

- forthcoming. "Natural Kinds in Biology," in Routledge Encyclopedia of Philosophy.

. ms. "What's Wrong With the New Biological Essentialism?"

Ghiselin, M.T. 1974. "A Radical Solution to the Species Problem," Systematic Zoology, 23, 536- 44 .

Glasgow, Joshua M. 2003. "On the New Biology of Race," The Journal of Philosophy., 100: 456-74

Godfrey-Smith, Peter 2000. "The Replicator in Retrospect," Biology and Philosophy 15: 403-23.

Goldberg, David 1993. Racist Culture. Cambridge, MA: Blackwell.

Goodman, Nelson 1955. Fact, Fiction and Forecast. Cambridge, MA: Harvard University Press.

Gould, S.J. 1977. "Why We Should Not Name Human Beings," in Ever Since Darwin. New York: W.W. Norton, 231-36.

Griffiths, Paul 1999. "Squaring the Circle: Natural Kinds with Historical Essences," in R. Wilson, ed., Species: New Interdisciplinary Essays, Cambridge, MA: The MIT Press, 209-28.

Griffiths, P. and R. Gray 1994. "Developmental Systems and Evolutionary Explanation," Journal of Philosophy 91: 277-304.

Hacking, Ian 2005. "Why Race Still Matters," Daedalus 134: 102-16. . 2007. "Natural Kinds: Rosy Dawn, Scholastic Twilight," in Anthony O'Hear, ed., The Philosophy of Science (Royal Institute of Philosophy Supplements Volume 61), Cambridge: Cambridge University Press, 203-39.

Hardimon, Michael 2003. "The Ordinary Concept of Race," Journal of Philosophy 100: 437-55.

Harding, Sandra, ed. 1993. The "Racial" Economy of Science: Toward a Democratic Future, Bloomington: Indiana University Press.

Herrnstein, Richard J. and Charles Murray 1994. The Bell Curve: Intelligence and Class Structure in American Life, New York: The Free Press.

Hull, David 1965. "The Effect of Essentialism on Taxonomy: 2000 Years of Stasis," British Journal for the Philosophy of Science, 15: 314-26, 16: 1-18.

- 1986. "On Human Nature," PSA: Proceedings of the Biannual Meetings of the Philosophy of Science Association 2: 3-13.

- 1994. "Contemporary Systematic Philosophies," in E. Sober, ed., Conceptual Issues in Evolutionary Biology, 2nd edition, Cambridge, MA: MIT Press, 295-330.

_. 1998. "Species, Subspecies, and Races," Social Research, 65: 351-67.

Kitcher, Philip 1999. "Race, Ethnicity, Biology, Culture," in Racism, Leonard Harris, ed., Amherst, NY: Prometheus Books, 87-117.

. 2007. "Does 'Race' Have a Future?” Philosophy \& Public Affairs, 35: 293-317.

Kripke, S. 1980. Naming and Necessity, Harvard University Press, Cambridge, MA.

Lewontin, Richard 1970. "Race and Intelligence," Bulletin of the Atomic Scientists (March 1970), 2-8. Reprinted in Ned Block and Gerald Dworkin, eds., The IQ Controversy. New York: Pantheon, 1976, 79-92. 
Lewontin, Richard, S. Rose, and L. Kamin 1984. Not in Our Genes: Biology, Ideology and Human Nature, New York: Pantheon.

Livingstone, F.B. 1962 "On the Nonexistence of Human Races," in The Concept of Race, ed. Ashley Montagu. New York: Free Press.

Mallon, R. 2004. "Passing, Traveling, and Reality: Social Construction and the Metaphysics of Race," Noûs, 38: 644-73.

- 2006. “Race': Normative, Not Metaphysical or Semantic," Ethics, 116: 525-551.

Matthen, Mohan 1998. "Biological Universals and the Nature of Fear" Journal of Philosophy 95: 105-32.

Mayr, Ernst 1942. Systematics and the Origin of Species. New York: Columbia University Press.

. 1959/1994. "Typological versus population thinking," in B.J. Meggers, ed., Evolution and Anthropology, Washington: The Anthropological Society of America, 409-12. Reprinted in Elliott Sober, ed., Conceptual Issues in Evolutionary Biology, Cambridge, MA: The MIT Press, 1994, 325-28.

- 1963. Animal Species and Evolution. Cambridge, MA: Harvard University Press. . 2002. "The Biology of Race and the Concept of Equality," Daedalus, 131: 89-94.

Millikan, Ruth G. 1999. "Historical Kinds and the "Special Sciences," Philosophical Studies, 95: 45-65.

Molnar, Stephen 1992. Human Variation. Englewood Cliffs, NJ: Prentice-Hall.

Nanay, Bence 2009. "The Properties of Singular Causation," The Monist, 92: 113-35.

.forthcoming a. "Population Thinking as Trope Nominalism," Synthese.

-forthcoming b. "Three Ways of Resisting Essentialism about Natural Kinds," in J.K. Campbell and M.H. Slater, eds. Carving Nature at its Joints. Topics in Contemporary Philosophy, Vol. 8, Cambridge, MA: MIT Press.

Nei, Masatoshi and Arun Roychoudhury 1993. "Evolutionary Relationships of Human Populations on a Global Scale," Molecular Biology and Evolution, 10: 927-43.

Okasha, Samir 2002. "Darwinian Metaphysics: Species and the Question of Essentialism," Synthese, 131: 191-213.

Oyama S., P.E. Griffiths, and R. Gray, eds. 2001. Cycles of Contingency: Developmental Systems and Evolution. Cambridge, MA: MIT Press.

Pigliucci, Massimo and Jonathan Kaplan 2003. "On the Concept of Biological Race and Its Applicability to Humans," Philosophy of Science, 70: 1161-72.

Platts, Mark 1983. "Explanatory Kinds," British Journal for the Philosophy of Science 34: $133-48$.

Putnam, H. 1975. Mind, Language and Reality, Cambridge University Press, Cambridge.

Quine, W.V. 1969. "Natural Kinds," in Ontological Relativity and Other Essays. New York: Columbia University Press, 114-38.

Rosenberg, Noah A., Jonathan K. Prichard, James L. Weber, Howard M. Cann, Kenneth K. Kidd, Lev A. Zhivotovsky and Marcus W. Feldman 2002. "Genetic structure of human populations," Science, 298: 2381-85.

Sesardic, Neven 2000. "Philosophy of Science that Ignores Science: Race, IQ and Heritability," Philosophy of Science, 67: 580-602.

Shelby, Tommie 2006. We Who Are Dark. Cambridge, MA: Harvard University Press.

Sober, Elliott 1980. "Evolution, Population Thinking, and Essentialism," Philosophy of Science, 47: 350-83.

Sterelny, K., K. Smith and M. Dickison 1996. "The Extended Replicator," Biology and Philosophy, 11: 377-403.

Van Fraassen, Bas 1980. The Scientific Image. Oxford: Oxford University Press. 
Walsh, Denis M. 2006. "Evolutionary Essentialism," British Journal for the Philosophy of Science 57: 425-48.

Wilkerson, T.E. 1995. Natural Kinds. Aldershot: Avebury.

Wilson, Edward O. and William Brown 1953. "The Subspecies Concept and Its Taxonomic Application," Systematic Zoology, 2: 97-111.

Wilson, Robert A, Matthew J. Barker, and Ingo Brigandt forthcoming. "When Traditional Essentialism Fails: Biological Natural Kinds," Philosophical Topics, forthcoming.

Zack, Naomi 1993. Race and Mixed Race, Philadelphia: Temple University Press.

. 2002. Philosophy of Science and Race. London: Routledge. 